\title{
Formation of Aromatic Siloxane Self-Assembled Monolayers
}

Susan L. Brandow, Mu-San Chen, Charles S. Dulcey, and Walter J. Dressick*

Naval Research Laboratory

Center for Bio/Molecular Science \& Engineering- Code 6900

4555 Overlook Avenue, S.W.

Washington, DC 20375 U.S.A.

*Corresponding Author. E-mail: wjd@cbmse.nrl.navy.mil

\section{Supplementary Figures}


Figure S-1: Brandow, et. al.
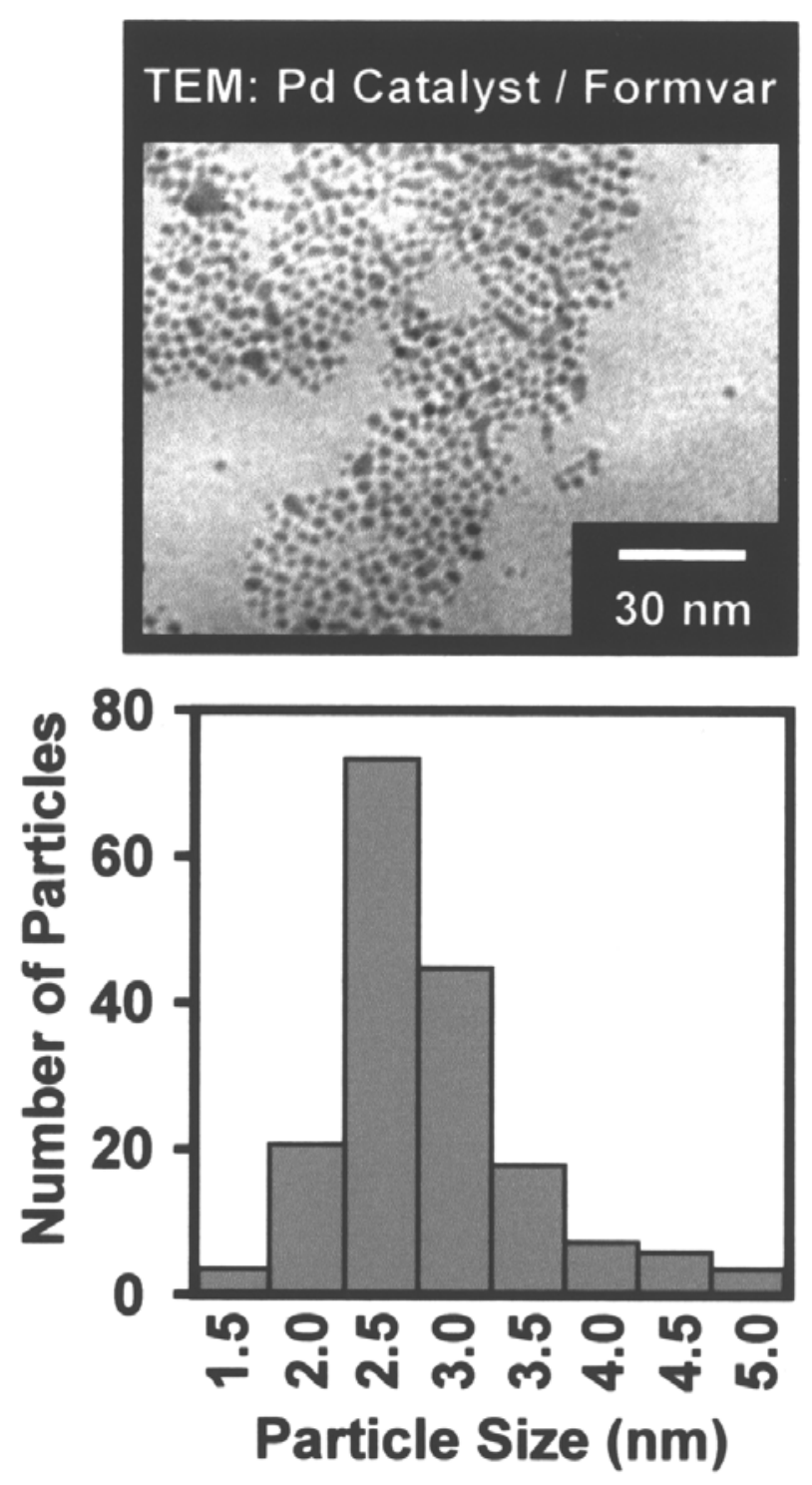

Supplementary Figure S-1: TEM of Pd Catalyst Particles with Histogram Showing Particle Size Distribution. 